UC-21

Reporting Date: June 1975 Issued: September 1975

\title{
Cold Cathode Investigation
}

by

John P. Rink

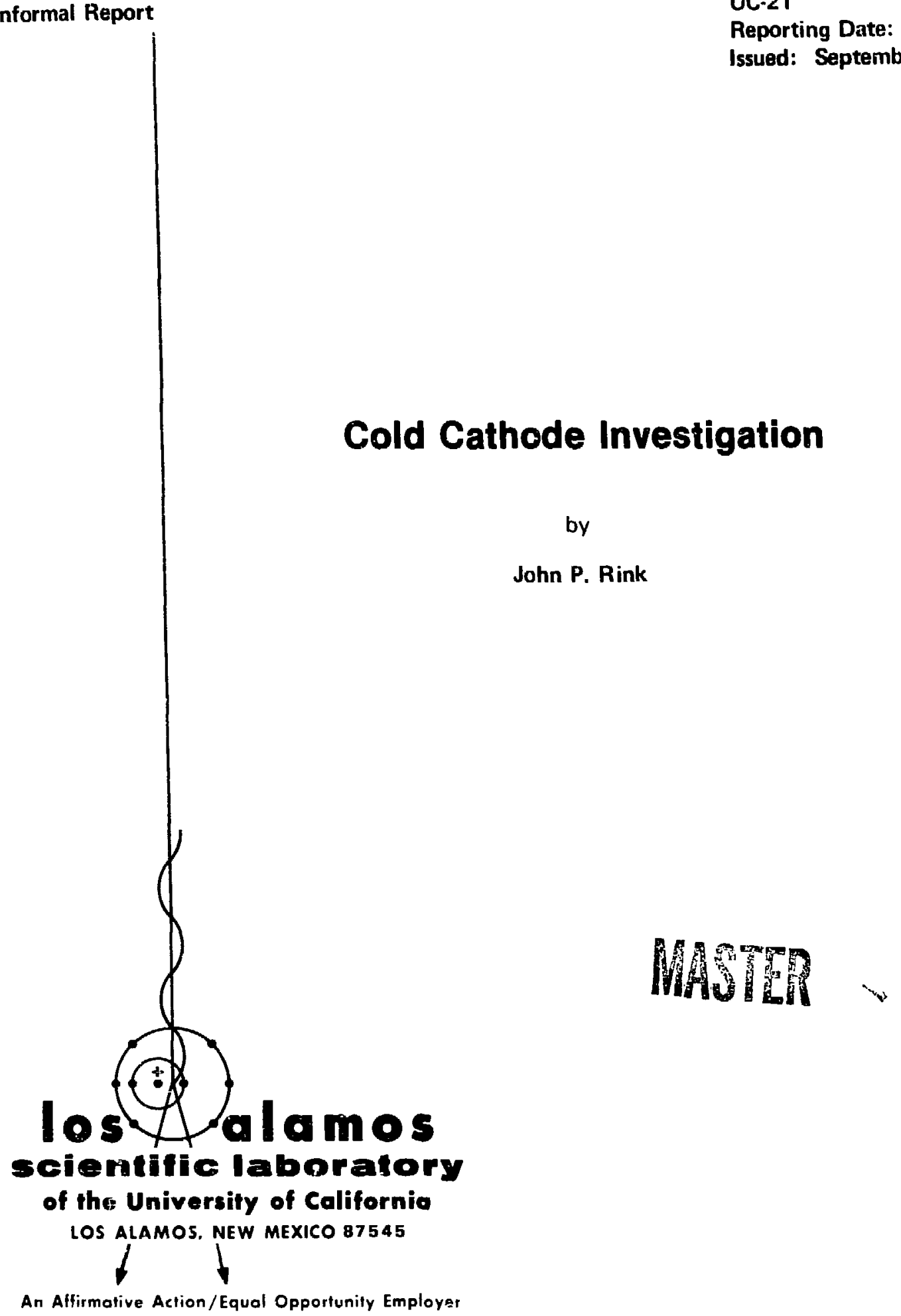


In the interest of f: wupt distribution, this report was not edited by the Technical Information staff.

\footnotetext{
Printed in the United States of America. Available trom National Tochnical Information Service

US Departmont of Commerce

5285 Port Royal Rood

Springtiald, VA 22151

Price: Printed Copy $\$ 4.00$ Mictotiche $\$ 2.25$
}

This report Fun prepared as an nccount of work pooneored bot the Uoited States Governoment. Neitber the Uniled Btaten minist-allion, nor any of their employees, nor any of their contractorn, ubbontrectors. of their employees. malet any tarranty, express or implied, of asuumea any leghil libitity of responsibility for the accuracy, complateners, of urefulases of any informafion, mpocraltus, product, or process dieclowed, of represents
ristic. 


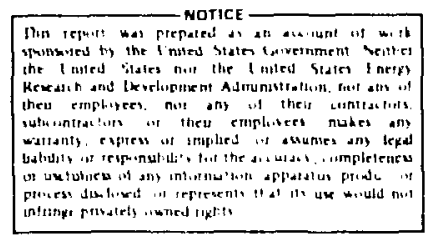

COLD CATHODE INVESTICATION

by

John P. Rink

\begin{abstract}
This report describes experiments for the evaluation of a cold cathode electron gun. Different anode and cathode materials and configurations were tried. Small signal gains of $6.3 \% / \mathrm{cm}$ were measured. It was found that the same small signal gains could be obtained with less energy deposition in the laser gas with the larger pre-ionizing currents from a cold cathode. Longduration pulses were observed that were limited only by the electrical energy available in the Marx bank.
\end{abstract}

․ INTRODUCTION

Uniform excitation of large volumes of atmospheric or higher pressure laser media by electron-beam stabilized discharges have been cemsastrate $=$ by many experiments. The earlies: of thes: devices utilized hot filaren:s as the soirce of electrons. ${ }^{1}$ More recent i icerature has described the work of several investigators using electron emissior from a cold cathode. $2-6$ This investigation of cold cathode performance was to evaluate the advantages and shortcomings of a cold cathode electron gun.

The term cold cathode, as used in this report, refers to a cathode that does not require any additional power to become a source of electrons when subjected to a sufficiently hig? field. Many different cathode materials and configurations were cencostrated to rork during these experiments. The only requirement found was for the eiectron-emitting surface to attain a fieic of approximately $10^{7} \mathrm{~V} / \mathrm{cm}$. Most of the enitting sursaces used were $0.006-\mathrm{mm}$ thick tartalum. Foils made of stainless steel, titanium, gold, and nickel worked equally well. A $0.013-\mathrm{mm}$ foil of aluminum failed structurally by bending flat against the foil-holding structure. An enitting surface formed by soldering 200 needles together in a 20 -mm-diameter bundle gave reproducible emission currents. A single reedle was not usable in a repetitive mode: the end point rapidly eroded, became blunt, and eventually either stopped emitting or became erratic in its emission.

\section{I . EXPERIMENTAL}

These cold cathode experiments were performed in two different devices, a 0.4 m-long by $0.3-m-i . d$. vacuum chamber, and a $1.4-m-10 n g$ by $1-m-i \cdot d$. vacuum chamber. The smaller device was used to make small signal gain measurements, while the larger device was used during the long-duratior. pulse studies. All electron trarsmiss was through a $0.020-\mathrm{mm}$ titanium foil.

The small signal gain is a good measure of the usefulness of a $\mathrm{CO}_{2}$ lasing medium. The small signal gain was measured over two different path lengths--one was $50-m m$ long and the other was $100-m m$ long. 


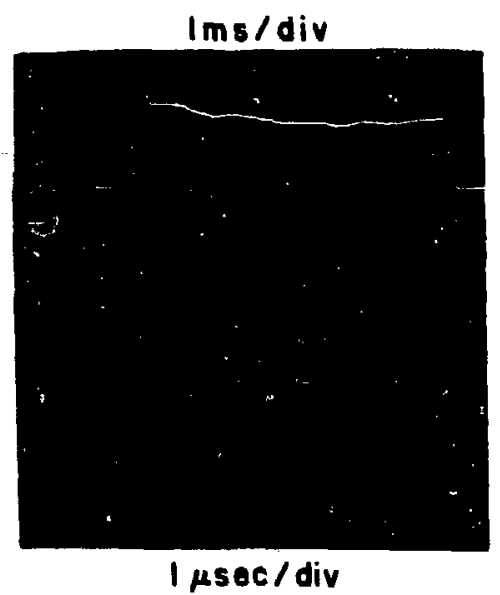

Fig. 1. Gain and current signals for tvpical experiment.

The path lengths were delineated br Lucite tubes inserted in the lasing medium. This known path length, coupled with a segmented anode 8 enables one to make accurate gain per unit length of active media measurements, as well as the energy deposition per unit volume. Short path lengths of active media were used to eliminate the problem of free oscillations that can occur in longer active paths.

Figure 1 shows the typical gain records obtained during a small signal gain experiment. This figure is a composite of

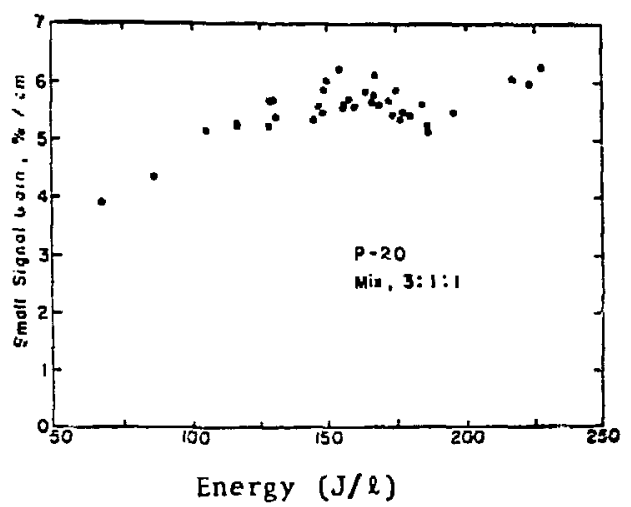

Fig. 2. Maximum small signal gain vs energy deposited in 3:1:1 mixture of He: $\mathrm{N}_{2}: \mathrm{CO}_{2}$, measured on $\mathrm{P}-20$ ine.

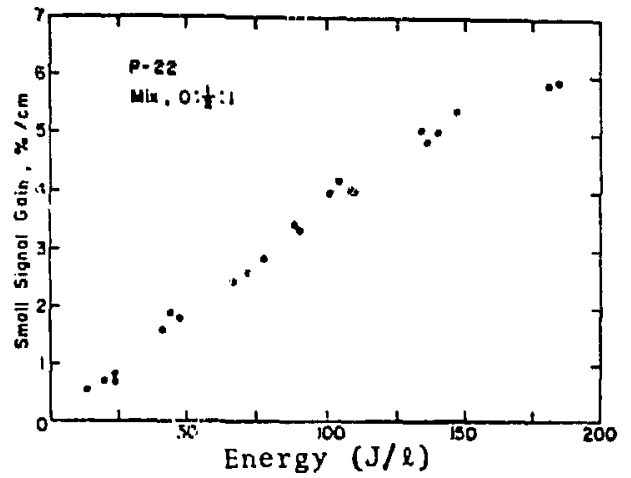

Fig. 3. Maximum small signal gain vs energy deposited in 1/2: 1 mixture of $\mathrm{N}_{2}$ : $\mathrm{CO}_{2}$, measured on $\mathrm{P}-22$ line.

two oscillograms. The upper trace is the entire gain signal $20-m V / d i v$ and $1-\mu s / d i v$; below it is the expanded gain signal at 10$\mathrm{mV} / \mathrm{div}$ and $\mathrm{l}-\mu \mathrm{sec} / \mathrm{div}$; the second from the bottom is the total lasing gas current at $4-k$ A/div and 1-us/div; and the bottom trace is the current in a $50-\mathrm{cm}^{2}$ segment of the anode, 82-A/div and 1-us/div. The laser gas for this experiment was a $3: 1: 1$ mixture by volume of $\mathrm{He}: \mathrm{N}_{2}: \mathrm{CO}_{2}$. The maximum small signal gain was a $5.6 \% / \mathrm{cm}$; this was achieved with an energy deposition of $170 \mathrm{~J} / 1 \mathrm{iter}$.

Figures 2, 3 , and 4 are plots for three different gas compositions of the measured maximum small signal gain vs the energy deposited in the gas. The laser gas

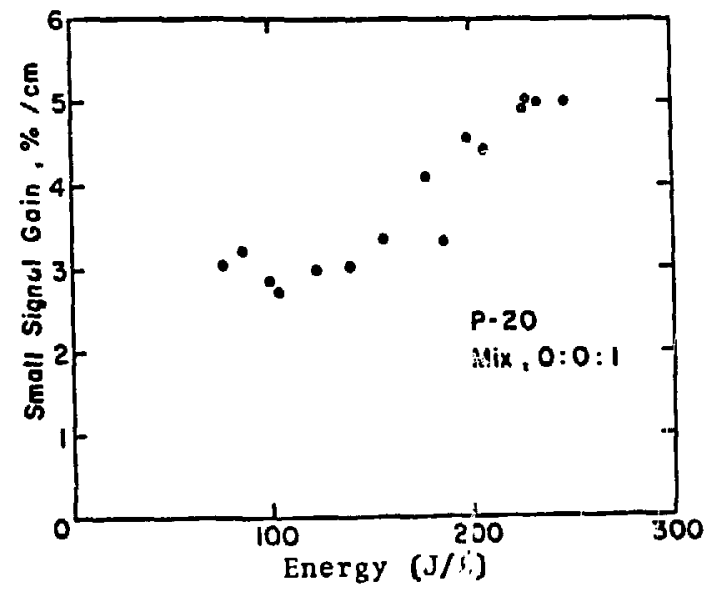

Fig. 4. Maximum small signal gain vs energy deposited in pure $\mathrm{CO}_{2}$, measured on $\mathrm{P}-20$ line. 
pressure in all the small gain experiments was 585 torr.

The small signal gain data was obtained with a wide variation of input parameters - the ionizing currents varied from $50-\mathrm{mA} /$ $\mathrm{cm}^{2}$ to $5-\mathrm{A} / \mathrm{cm}^{2}$; the ionizing current accelerating potential was varied from $120 \mathrm{kV}$ to $170 \mathrm{kV}$; the current pulse lasted from $1 / 2$ us to $4 \mathrm{Hs}$; and the field strengths in the laser gases were varied from $3.8 \mathrm{kV} / \mathrm{cm}$ to $6.5 \mathrm{kV} / \mathrm{cm}$. These changes in parameters account for most of the scatter in the data. vote that the $\mathrm{N}_{2} / \mathrm{CO}_{2}$ data in Fig. 3 was measured on the $P-22$ line, while the data in Figs. 2 and 4 were measured on the $P-20$ line. Small signal gains on the P-22 line are about 10 : less than those measured on the P. 20 line.

Figure 5 shows an unexpected result of this cold cathode reseatch. The dots are the $3: 1: 1$ data shown previously in Fig. 2; the triangles are data taken at Los Alamos Scientific Laboratory using a hot filament device. ${ }^{8}$ Nore that in addition to the higher small signal gains achieved, gains of the same value were attained with less energy deposition in the gas. This was achieved through higher electron gun currents and usually higher fields across the laser gas. The field strength in the laser

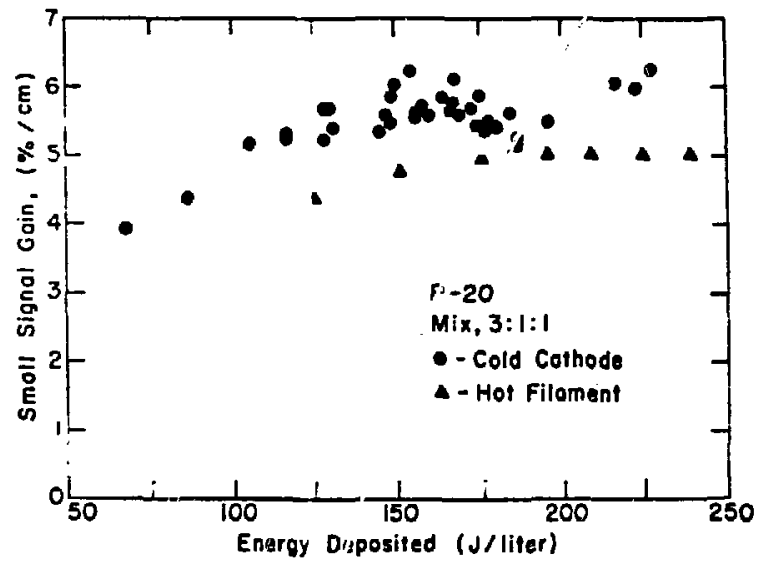

Fig. 5. Small signaj gain vs energy deposition.
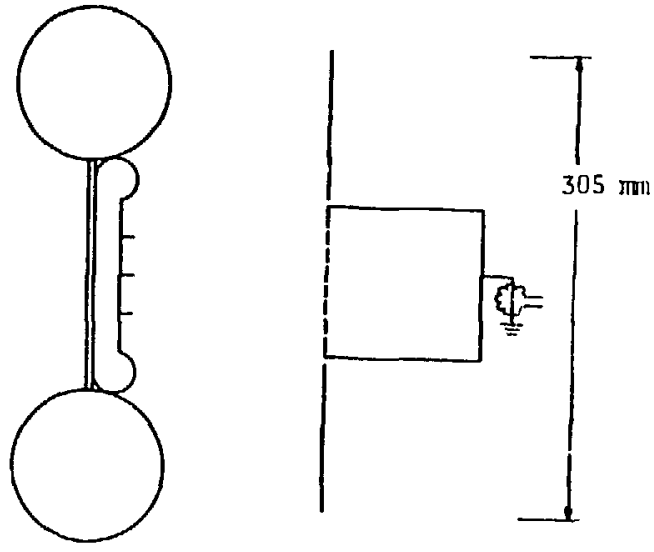

Fig. 6. Long pulse electrode configuration.

gas for the hot filament device was $5 \mathrm{kV} / \mathrm{cm}$, and the current pulse duration was $10 \mathrm{\mu s}$. In all of the hot filament experiments, a maximum small signal gain was achieved before the end of the current pulse. In on $1 y$ three cold cathode experiments did the sinall signal gain reach a maximum before the end of the current pulse.

The large vacuum vessel previously mentioned was now utilized to investigate how long-duration pulses could be obtained. The larger vessel was used to minimize wall effects. Figure 6 shows an electrode configuration that produced long-duration pul$s \in S$, pulses lasting as long as $14 \mathrm{Hs}$. The cathode was comprised of a $355-\mathrm{mm}$ torus behind the foil support structure. The anode was a flat, circular plate $305 \mathrm{~mm}$ in diameter. The box represents a Faraday cup behind an 0.020-mm titanium foil. This arrangement was used to measure the transmitted current through the center $126 \mathrm{~cm}^{2}$ of the anode.

varying the number of foils in the cathode, the foil material and foil pro. jection height had little effect on the guncurrent amplitude or pulse duration. The anode surface had the greatest effect on the cold cathode performance in these experiments. Anodes of aluminum and one made by electroplating gold on brass produced higher currents and shorter duration pulses. 


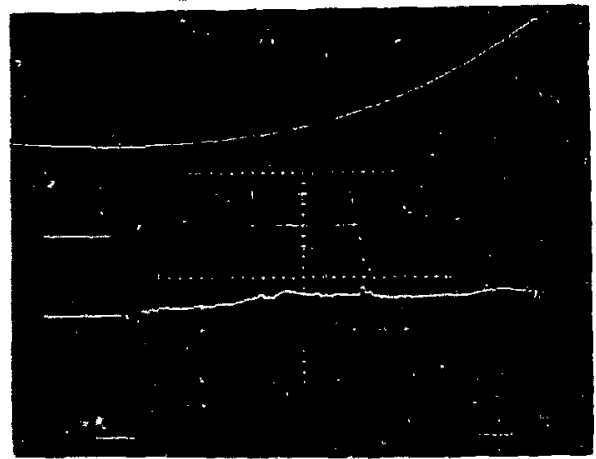

$1 \mu \mathrm{sec} / \mathrm{div}$

Fig. 7. Long-duration pulse; $120 \mathrm{kV} ; 5-\mathrm{cm}$ electrode spacing; and $5000 \mathrm{~A} / \mathrm{div}$.

The gold plating was not adequate; and af ter about 10 pulses, all the gold in the center $100 \mathrm{~cm}^{2}$ of the anode had been removed. The pulse duration and current amplitude then returned to those values obtained with a plain brass anode. This is in agreement with an observation during experiments on the smail cold cathode device. The current pulse in the small device increased in duratior from 2 us to 4 us when a Lucite isolition plate around the anode was replaced with a stainless steel plate.

Pulse duraticas of 8-10 hs were obtained routinely at electrode spacings of 5 to $25 \mathrm{~cm}$ in the larger cold cathode chamter. Figure 7 shows the gun voltage and total current as a function of time. The only limiting parameter in this experiment was the depletion of the energy stored in the Marx bank, which was comprised of five $0.7-4 F$ capacitors rated at $50 \mathrm{kV}$ each.

This gave a system capability of $0.14 \mu \mathrm{F}$ at $250 \mathrm{kV}$. From the ringing frequency after an arc, a system inductance of $1.6 \mathrm{uH}$ was calculated

Figure 8 shows a long-duration pulse terminated with an exponential current increase in the last portion of the pulse. Figure 9 is a composite of two oscillograms --the upper trace is the voltage, the middle trace is the total gun current, and

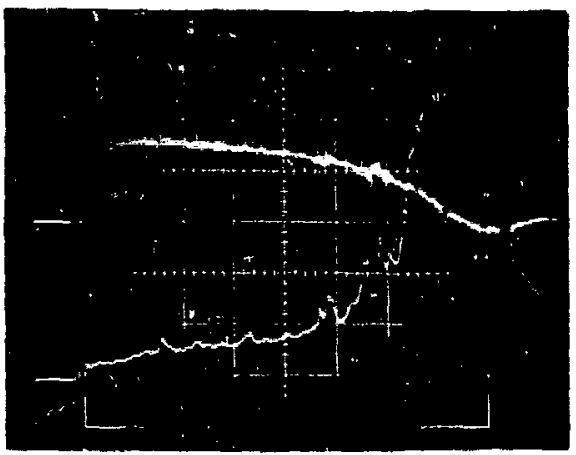

$2 \mu \mathrm{sec} / \mathrm{div}$

Fig. 8. Pulse termination by exponential curtent increase; $180 \mathrm{kl} ;$ and $15 . \mathrm{cm}$ electrode spacing.

the bottom trace is the current transmitted through a $0.020-$ lum titanium foil. Sote how the transmitted currant drops to zero when the electrode voltage drops below $90 \mathrm{kl}$.

The currents were measured with Pear. son current transformers, which have a time response of less than $0.1 \mathrm{is.}$. Voltage $\mathrm{sig-}$ nals were obtained by measuring the current in a copper sulfate resistor connected externally between the carhode and anode of the electron gun.

vacuum requirements for a cold cathode were found to be quite minimal. Satisfactory electron emission was observed in the

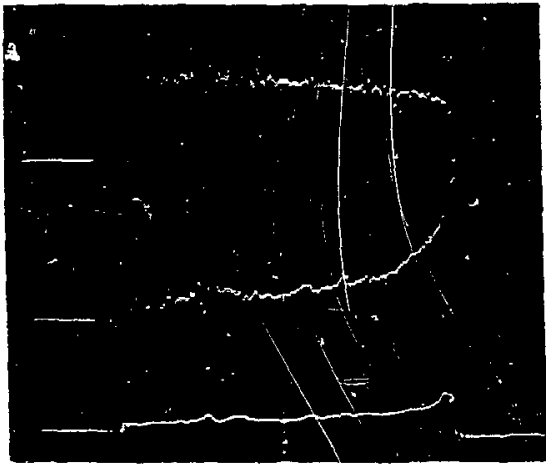

I $\mu$ sec/div

Fig. 9. Total and transmitted currents; $180 \mathrm{kV}$; and $10-\mathrm{cm}$ electrode spacing. 
vacuum regime of $3 \times 10^{-4}$ to $6 \times 10^{-7}$ torr. Work hy other investigators has shown that electron emission from a cold cathode starts from a field emission process. To prozide the large currents during a pulse, a plasmia then has to form around the emitting surface. This plasma is probably formed hy ions falling back on the cathode. If the field-forming electrodes are of the proper form, the cons will all be constrained :o fall back on the thin foil that provided the initial emission. The small clectron gun was a good example of improper alectrode configuration. From photographs of the discharge and pitting of the small athode clectrode, it was ascertained that the cathode was emitting in a 4 ." geometry to all the inner surfaces.

\section{CONCLUSIONS}

The coil esthode gun has produced larger small signal gain with tess energy deposition in the laser gases than has been achieved with hot filament devices. The use of cold cathodes in proposed large $\mathrm{CO}_{2}$ amplifiers results in savings through sim. plicity of thi cathode structure and no need for filament heating power. However, cven with all the advantages, the cold cathode is not geing to replace all the hot filament devices. Cosd cathode has several disadvartages, such as (1) The nonrepeatability of current pulses, which is greatly dependent upon the device geometry; (2) The current pulse shape is not constant as a function of time; (3) Pulse durations of most cold cathode devices are still too short: (4) Due to the large currents and depletion of the charge on the capacitor, the electron energy can vary as a function of time; and (5) The higher currents associated with cold cathodes nlace additional demands on the power supplies for a cold cathode amplifier device, specifically in terns of capacity and inductance. In spits. of these shortcomings, cold cathode devices have demonstrated capabilities no: at tainatle with hot filament machines.

\section{ACKNOWLEDGMENTS}

i thank Wallace Leland and Murlin

Noiter for their helpful comments and suggestions: 1 also acknowledge the excei:ent a ic of Kenneth Timblin and Bill Bentley in bujlding the equipment and performing the experiments.

\section{REFERENCE.S}

1. C. A. Fenstermacher, M. J. Nutter, $K$. $T$. lel and, and $\mathrm{K}$. Bover, Bull. Am. Frys. Soc. $16,42(1971)$.

2. G. Loda, "Measurements on a High Power 10u Atmosphere $\mathrm{CO}_{2}$ Discharge Laser", 8.11 . Am. Phys. Soc. 17, 681 (May 1972).

3. H. G. Ahlstrom, G. Inglesakis, J. $\vec{F}$. Holarichter, T. Ran, J. Jansen, and A. C. Kolb. "Current, Voltage and Gain Measure. ments in a High Current Electron Beam $\mathrm{CO}$ Laser" "3rd Conference on Chemical and Molecular Lasers, St. Louis (May lg:2).

4. G. Dezenberg, C. Cason, and R. Huff, Paper 22.4, Technical Digest, IEEE inte:national Electron Devices Mtg., Kashingcon "D. C., 1973.

5. B. B. O'Brian, Appl. Phys. Lett. 22, 503 (1973).

6. R. O. Hunter, Conference on Laser Engineering and Applications, Washington, $D$. C., May 1973.

7. G. K. Kartsev, Soviet Physics - Doklady 15,475 (1970).

8. W. T. Leland, M. J. Nutter, J. P. Rink, C. A. Fenstermacher, "Characteristics of High Pressure Carbon Dioxide Laser Ampli. fiers Pumped With Electron Beam", Gaseous Electronics Conference, London, ontario, October 1972 . 